\title{
Pathophysiology of Zika Virus; From Infection to Cure
}

\author{
Asifa Shina Muzaffar \\ Department of Biochemistry Government College University Faisalabad, Pakistan. \\ Zahed Mahmood \\ Department of Biochemistry, Government College University Faisalabad, Pakistan. \\ Muhammad Jahangeer \\ Department of Biochemistry, Government College University Faisalabad, Pakistan. \\ Areej Riasat \\ Department of Biochemistry, Government College University Faisalabad, Pakistan. \\ Shoukat Hussain \\ Department of Biochemistry Government College University Faisalabad, Pakistan.
}

*Corresponding Author: Muhammad Jahangeer Email: rajahangeer@gcuf.edu.pk

\begin{abstract}
:
Zika virus is an icosahedral, enveloped, single-stranded RNA virus, a member of the family Flaviviridae, transmitted to humans by Aedes species mosquitoes. Unique features of Zika virus infection are sexual and transplacental transmission and associated neurological morbidities. The main objective of our review is to summarize the most of current information including epidemiology and pathophysiology of routes of transmission, prevalence, mode of infection, symptoms, diagnosis, treatment and vaccine strategies of Zika viral infection. This article is helpful to improve the treatment of Zika viral infection which will be beneficial for society. There are two different methods to diagnose the viral infection through RTPCR and RNA NAT analysis. Vaccines have been developed against Zika virus, DNA vaccine effects actively than $m R N A$ and live attenuated vaccines, due to its unique mode of infection. Treatment of Zika fever is supportive and primarily involves acetaminophen for fever, headache, or myalgia. ZIKV illness is generally mild in nature, requiring no specific treatment. As with treatment for dengue, nonsteroidal anti-inflammatory agents should be avoided if thrombocytopenia is present. The most successful trials are given by the DNA and mRNA vaccine which act by targeting the genome of the Zika virus or by inhibiting its protein synthesis mechanism.
\end{abstract}

\section{Key words:}

Zika virus, Flaviviridae, zika viral infection, RT-PCR, RNA NAT analysis, Acetaminophen

\section{Introduction}

Zika virus initially identified in Zika forest in Uganda in 1947. Aedes species mosquito is main source to spread in humans. ZIKV belongs to family Flaviviridae. (Wikan \& Smith, 2016). Zika virus has icosahedral shape, enclosed, single-stranded RNA virus. It is covered with lipid enclosed layer with thick projections which contain packed glycoproteins (Bennett et al. 2014). ZIKV is single stranded RNA which is transmitted through mRNA. The viral genome consist of polyprotein and 3419 amino acids that has been processing as co and post translation in host and viral proteases (Haddow et al. 2012). Zika virus has emerged about few years ago and there were huge epidemics in States of America and Pacific Area. The major causes toward 
spreading the Zika virus are unidentified, but it is considering that Aedes species mosquitoes can be a reason in humans in built-up areas. Zika viral infection is transmitted through sexual and vector transmission which causes the neural syndroms for example Microcephaly and Guillain-Barré syndrome (Barzon et al. 2016).

At that time, the identification of Zika infection was identified surprisingly in rhesus monkey because there was no outbreak in humans. In 1952 the very first human case was testified (Kindhauser et al. 2016). ZIKV was known as an arbovirus. Later on, various means of infection were identified. 57 countries testified Zika V, 18 species of mosquitos were considered as major cause of zika infection in the continents of Africa and Asia. Initially the major outbreak of the neurological syndrome was reported in Brazil in 2015. Zika causes the major complications in conceive, premature birth, miscarriage and complications related to eyes (Yitades et al. 2016). In 2016 because of increasing rate of zika infection, WHO pronounces ZIKV, a big threat for health problems in public. Late 2016 researchers revealed mode of transmission and pathophysiology of Zika $\mathrm{V}$ that helps to diagnose and treatment against zika infection (Boeuf et al. 2016).

ZIKV is basically transmitting by biting of diseased mosquitoes of Aedes species. Zika viral infection is transmitting by sexual and liquid transmission (Musso et al. 2015). The basic symptoms of Zika V are temperature, rashes, infection in eyes, headache, fatigue in muscles and joints. Different animal models such as rats, mouse and rhesus monkeys were used to understand the mechanisms of transmission of zika infection (Boeuf et al. 2016). Various methods are used for diagnosing the zika infection through collection of serum, urine, saliva before 40 days of infection. RT PCR is also used for diagnosing the infection in humans. Zika infection is also diagnosing in pregnant females during second trimester of pregnancy (Hennessey et al. 2016).

The ZIKV reproduction starts by attachment of RNA virion with cell membrane of host cell through enclosed proteins which boosts endocytosis. Later on, the membrane of the virus combines with membrane-bound compartment inside host cells and the virion enters into cytoplasm of the host cell. Then the translational process begins and different proteins cuts. Due to this process the structural and nonstructural proteins forms. The further step is replication and produces double-stranded RNA (dsRNA) that present in the cytoplasm of endoplasmic reticulum (ER) which considered as viral factory. The process of transcription occurs to produce other single-stranded RNA that accumulate in the Endoplasmic Reticulum to produce new virions. The virions shifted to the Golgi bodies and causes the infection in different new cells after releasing into the intracellular spaces of Golgi bodies. Different techniques are established by scientists that reducing the effects of infection caused by ZIKV. Many researchers are performing different experiments to develop the vaccination against zika infection but there is no proper vaccination which can be suggested for zika infection. But one antibiotic is recommended now a days by doctors that is Duramycin which reduce the effect of infection in patients. DNA vaccine, Live attenuated vaccine and mRNA vaccine has been developing but most appropriate vaccine is DNA vaccine because of its effectual mode of mechanism (Fernandez \& Diamond, 2017).

A recent outbreak of ZIKV is stated in the neighboring countries like India and China which are near the boundary of Pakistan. It is a possibility of infection ZIKV in Sindh province of Pakistan in near future. (Fatima et al. 2016). There is no confirmed case of ZIKV is reported in Pakistan, this can be due to same symptoms of DENV and CHINKV. The fear is increasing day by day of ZIKV epidemic in Pakistan because the scenario of Zika's rampage in Pakistan will be much dangerous than Brazil due to its high rate of birth per day (Wahib et al. 2018). 


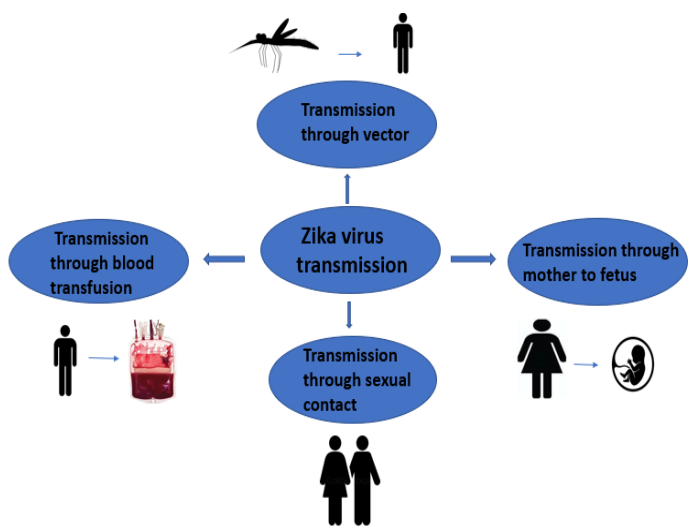

Fig. 1: Mode of Transmission of Zika V

\section{Transmission through vector}

Aedes species mosquito transmitted the zika infection in tropical and subtropical areas. Chikungunya (CHIKV) and virus dengue (DENV) are also transmitted by Aedes species mosquito. ZIKV is transmitted through sylvatic cycle in other than human (Yitades et al. 2016; Petersen et al. 2016). Actually, United States is located mostly on suburban areas where these Aedes species of mosquitoes are present in large number. The spread of zika infection is controlling through different techniques and methods by reducing the number of Aedes species mosquitoes. Humans are basic cause of transmission of zika infection in cities. Infact, the United States contain excellent observation methods which are used to detect early pathogenic effects (Aliota et al. 2017).

\section{Epidemiology}

Zika infection is transmitted through sylvatic cycle includes fda and in Aedes species mosquitoes in Africa. Like yellow fever, zika infection it is considering that zika infection is also transmitted in Aedes species mosquitoes through sylvatic cycle. ZIKV is not transmitted through sylvatic cycle in Asia because there is no case is reported. Actually, the investigation for sylvatic transmission for arbovirus is absent in Asia. The group of ZIKV, CHICKV, DENV and yellow fever is known as arboviruses which can be a source of transmission through sylvatic cycle. In addition, in humans the sylvatic cycle is not clear due to no investigation and medically diagnosis of related Aedes species mosquitoes (Gregory et al. 2017). In Africa, the population shows $26 \%$ prevalence of antibodies against zika infection in Angola. Through ELISA on immunoglobulin M, it was investigated that $5 \%$ to $8 \%$ zika infection was detected in blood samples of 3 different groups of clinical patients (Herrera et al. 2017). But it is not still clearly defined about results between sylvatic cycle and spread zika viral infection in different cities. Pacific Islands, South America and North America also facing the problem of zika infection. There are millions of cases are reported through urban transmission cycle in current years.

\section{Biology and Pathophysiology}

Aedes species mosquitoes contain sub classes which are Aedes (Fredwardsius), Aedes (Stegomyia) and Aedes (Diceromyia). Subgenera including Aedes africanus, Aedes furcifer, Aedes vittatus and Aedes luteocephalus has been declared as way of spread in Africa (Diallo et al. 2014; Diagne et al. 2015). In Africa there is less information about presence of ZIKV. There is an indication about presence of zika infection in non-human primates in different countries of continent of Africa that lies south of the Sahara includes the Uganda, Central African Republic, Nigeria, Ethiopia, Senegal and Gabon (Musso \& Gubler, 2016). According to current investigation in green monkeys and baboons of Africa shows $16 \%$ infection of ZIKV but no case is reported for humans (Buechler et al. 2017). Therefore, according to recent investigation there is an evidence indicates 
in which NHPs show a dangerous character in transmission of virus in Africa. According to the serological inquiries, it was stated that there are many antibodies working hostile to ZIKV in different animal because they show a vital role in transmission of zika infection (Ragan et al. 2017).

Incomplete information is present related to the naturally inducing infection in NHPs but the indication of ZIKV in blood (viremia) experimentally proved that infected vectors can infect the other vectors of this family (Haddow et al. 2017). Using the animal models for ZIKV is helpful to know about mode of transmission (Althouse et al. 2016). Aedes species mosquitoes aegypti are associated with zika infection in cities. While there are two more Aedes (Stegomyia) species, Aedes hensilli and Aedes polynesiensis, they were considered for major epidemic in Yap State, Micronesia a state of Federation and in French Polynesia (Ledermann et al. 2014). Aedes aegypti is commonly dispersed in all the tropic and sub-tropic areas of the world. In the United States, it is widespread in all US Virgin Islands and Puerto Rico and different areas of the contiguous United States and Hawaii (Petersen et al. 2016; Hahn et al. 2016). In April 2017, it was suggested that there are also some other sources of transmission in United States, these were shown the resemblance with transmission of DENV and different other arboviruses which were transmitted by Aedes species mosquitoes (Radke et al. 2012; Thomas et al. 2016). Survey about DENV eruptions in the continent of United States was specified through infrastructural factors like air-conditioner is related with lower levels of infection (Radke et al. 2012; Reiter et al. 2003).

ZIKV also transmitted through infected Aedes species mosquito and infected saliva of the infectious blood after biting the infected person, research indicated the high capability of zika infection outbreaks by this transmission (Li et al. 2017), some researches show less (Diagne et al. 2015; Chouin et al. 2016). Somehow it is depending upon the presence of Aedes species mosquitoes and mode of transmission in that area (Roundy et al. 2017; Ciota et al. 2017; Pompon et al. 2017). The study of genotypes of Aedes species mosquitoes of Africa and Asia show high capability of vector (Roundy et al. 2017; Ciota et al. 2017). Nevertheless, Aedes species mosquitoes are considered that they contain the high capability of zika infection transmission while suckling blood from humans and bite several humans in one blood meal and lives near to the humans (Gubler et al. 2002).

Transmission through mosquitoes of ZIKV in Ae. aegypti is confirmed, while the mountainous of infection is not known (Thangamani et al. 2016; Ciota et al. 2017). ZIKV is recognized in greater than 25 species of mosquitoes (Diallo et al. 2014; Althouse et al. 2015; Ayres et al. 2016). In particular, the role of Aedes albopictus and Aedes Culex species mosquitoes in transmission of virus is discussing. In America there are only to species f mosquitoes are identified. According to review of transmission through vector in Gabon there is only Ae. Albopictus species of mosquitoes which transmit the (Grard et al. 2014). While in United states and Europe there is no identification of ZIKV by Ae. Albopictus, the infected travellers returning in 2016 (Ciota et al. 2017). According to different studies related to check the difference infection by Aedes aegypti and Aedes Albopictus. It has been confirmed that capability of infection is higher in Ae. aegypti than Ae. Albopictus. The probable role of Culex mosquitoes in transmission zika infection is discussed (Leal, 2016). Majority of studies shows that there is no role of Culex mosquitoes in zika infection transmission (Heitmann et al. 2017). The other species of Culex like Cx. quinquefasciatus and Culex tarsalis are also not involed in transmission of ZIKV (Liu et al. 2017; BL \& Rasgon, 2017).

\section{Transmission through sexual contact}

Transmission through sexual contact of Zika virus can also be transported from infected person to healthy person. Zika virus transmitted through sexually from man to his female partner in 2016 according to case study (Yitades et al. 2016). Mostly the virus spread through travellers from one place to other. In most cases sexual contact happened before showing the symptoms of infection, in some cases sexual contact happened during appearance of infectious symptoms in infected person and after short time period the zika inflectional symptoms confirmed, after replication of ZIKV and RNA of virus was present in diseased person (Mansuy et al. 2016). Mostly the symptoms are appeared after sexual transmission but usually after sexual transmission of zika infection it remains asymptomatic at time of sexual intercourse. 
Male to female transmission is usually common, but there are some cases reported as transmission through sexual contact from male to male and other one is from female to male. Sexual transmission is increasing day by day that's why they are recommended to use the protection during sexual intercourse in case of zika infection (Boeuf et al. 2016).

\section{Epidemiology}

Initially transmission of zika virus through sexual contact has been stated in 2008 (Foy et al. 2011). An American scientist was returned to his home after six days, he got haematospermia and some other symptoms of zika infection. After four days of his returning to home, his wife did not travel internationally in past years, after their sexual contact the symptoms were shown in his wife. The results of serologic analyses of acutephase and convalescent-phase paired sera reliabled with zika viral infection but hard work to detect zika virus nucleic acid. But worked to isolate virus from serum were failed. Mosquitoes vector of Aedes species for zika virus is not detected in the topographical region near to their home actually there were no vector species around their home according to precise investigation.

Moreover, in eruption of 2013 in French Polynesia, the indication for transmission through sexual contact was providing by the recognition of a high zika viral RNA load and exhibiting haematospermia (Musso et al. 2015). In start of 2016, the major eruption in the state of America was through sexual contact as mode of transmission was confirmed after experiences with travellers who came back from their foreigner trips of infected countries like Europe. According to another outbreak in 18 April 2017, there were more than 40 cases of sexually attained zika viral infection in US by CDC (Centres for Disease Control). Mostly it is recognized that the sexual transmission occurred as symptomatic from man to woman, from woman to man and from mam to man (Deckard et al. 2016; Davidson et al. 2016), but in some cases this transmission occurred asymptomatic from male to female (Brooks et al. 2016; Freour et al. 2016).

\section{Biology and Pathophysiology}

ZIKV infection in human semen can be detected by two methods: one is through RT-PCR (reversetranscription polymerase chain reaction) that identify the ZIKV RNA. The next one is by passing the amplification in culture through demonstrate of virus. Sometimes it becomes difficult to find out the ZIKV infection by occurrence of RNA because RNA has not been always specifying the presence of zika viral infection. ZIKV RNA was identified in human semen, which was testified within 188 days after initiation of infection and it was the longest published time, usually it does not happen it was a rare case (Nicastri et al. 2016).

After initiation of the zika viral infection was culturable from human semen its was estimated that 69 days are considered as the longest published time (Arsuaga et al. 2016). But it becomes difficult due to methodological issues that makes it simplifying through that single report. ZIKV RNA has been identified after inoculation within 5 to 7 days in two cell culture, however there was not any change is zika viral infection RNA copy number in inoculum and they found no data while in plaque formation and in cytopathic effect in the cell culture passage. Other publications usually reported the culturing of zika virus infection upto 24 days after starting the infection (D'Ortenzio et al. 2016). It is not clear yet which component in human semen is involves in viral infection of ZIKV, but it has been detected in ZIKV RNA in human semen without presence of spermatocytes due to vasectomy (Arsuaga et al. 2016). It has been also detected in ZIKV RNA in human semen without presence of spermatocytes due to azoospermia (Freour et al. 2016). The removal of spermatocytes in done by centrifugation of human semen (Barzon et al. 2016).

Through immunofluorescent staining the antigens of Zika viral infection have been imagined in the head of spermatocytes of the infected man (Mansuy et al. 2016). Through in situ hybridization ZIKV RNA became detectable directly on the top and flagellum of spermatocytes by immunized mice (Govero et al. 2016). In case of females, data collected through cases of different reports and collected from female members in the Puerto Rican which specifies that detectable Zika viral RNA in vaginal excretions is rare but it is limited in duration usually less than 14 days (Aubry et al. 2016; Paz-Bailey et al. 2017). Mouse models that are used to study are suggesting that vaginal shedding can be pretentious in limited timing during the estrus cycle and 
pregnancy status (Tang et al. 2016). There is only one case of sexual transmission of ZIKV from female to male that was held during menstruation of female.

\section{Transmission through blood transfusion}

The risk of transmission through blood transfusion had related to after the identification of the RNA virus into the blood of the normal donor shown in Fig. 3. There were two cases on January $16^{\text {th }}, 2016$ which were reported in Brazil that described the transmission of ZIKV through transfusion of blood from infected person to the healthy person. They made an investigation according to the rules of that hospital of the procedure of the unwanted things which are associated with the blood transfusion, the two patients and with the giver to provide a written rational assent. The two samples that were collected from the donor before and after the transfusion of blood were negative for CHIKV and DENV on the RT-PCR. However, this sample was positive for ZIKV, after it they tested the urine of 14 days later onset of symptoms was also positive for ZIKV (Govero et al. 2016).

\section{Epidemiology}

Inquiries in Brazil have investigated three possible transmissions of ZIKV which are associated with blood transfusion (Motta et al. 2016; Barjas-Castro et al. 2016). In 2002, there is a validation of 23 infections of West Nile Virus spread through blood transfusion and their products in the US in 2002 (Pealer et al. 2003). In unites state universal screening of blood products is done through a delicate nucleic acid test (NAT). From early 2013 to late 2014 a major eruption of ZIKV in French Polynesia, ZIKV RNA was observed in $2.8 \%$ of non-symptomatic persons who donated blood by a technique of RT-PCR (Musso et al. 2015).

\section{Biology and pathophysiology}

Stop of transmission of ZIKV needs to reduce the blood products and to identify the infectious blood products through blood screening laboratory tests and their removal from blood. Pathogen reduction technology (PRT) has been recognized to be operative in deactivating ZIKV for blood and RBCs (Laughhunn et al. 2017). By Department of Health and Human Services, it is their responsibility to defend the safety of the blood supply involved the importation of blood products from genuine areas in the continental United States. The treatment of plasma and apheresis platelets is done by with PRT. Starting in early April 2016, individual donor screening for ZIKV by NAT under an IND authorization was established. In June 2016, 2 blood screening nucleic acid tests were available in IND applications in the United States. During the peak of the eruption, $1.8 \%$ of donated blood products had obvious in ZIKV nucleic acid (Adams et al. 2016; Kuehnert et al. 2016). To date, 325 presumptive viremic donors in Puerto Rico have been recognized (Atlanta, 2017).

219 blood presumptive viremic donors in the continental United States and Hawaii have been recognized through available of NAT screening assays in IND. The first 14 probable ZIKV infections identified in blood donors from the continental United States were described in detail by Galel and colleagues (Galel et al. 2017).

\section{Maternal transmission of Zika virus}

Maternal transmission of ZIKV in done during pregnancy. It is suggested that zika viral infection is passed on from maternal to fetus during pregnancy (Villamil et al. 2016). The ZIKV RNA is identified in the amniotic fluid. The fetus has cerebral grazes supposed by echography. According to a research, 40 to 54 antigens and several viral RNA have been reported in the CNS of the placentas. There are also some new born babies with neurological syndrome microcephaly and they died soon due to indication of ZIKV in their blood samples. But the main reasons of these diffusion are still not recognized. According to a case study, there were three cases of perinatal transmission of ZIKV in the children. The ZIKV RNA was indicated in the two children, one of them was asymptomatic in whole route of transmission and other one had the light eruption and the thrombocytopenia as describe in Fig.1 (Jimenez et al. 2017). 


\begin{tabular}{|l|l|l|l|}
\hline Year & Country & Prevalence (\%) & References \\
\hline 1952 & India & 16.8 & (Duonget et al. 2017) \\
\hline 1953 & Philippines & 12.4 & (Duonget et al. 2017) \\
\hline 1953,1954 & Malaysia & 75 & (Duonget et al. 2017) \\
\hline 1953 & Malaysia & 19 & (Duonget et al. 2017) \\
\hline 1953 & Borneo & 18 & (Duonget et al., 2017) \\
\hline 1954 & Thailand & 16 & (Duonget et al. 2017) \\
\hline 1977,1978 & Indonesia & 3.2 & (Duonget et al. 2017) \\
\hline 1983 & Indonesia & 12.7 & (Duonget et al. 2017) \\
\hline 1983 & Pakistan & 2.3 & (Duonget et al. 2017) \\
\hline $1996-1997$ & Borneo & 44.1 & (Duonget et al. 2017) \\
\hline 2001,2012 & Thailand & 9.5 & (Wikan et al. 2016) \\
\hline 2012,2014 & Thailand & 4 & (Buathong et al. 2015) \\
\hline 2012 & Philippines & 0.37 & \\
\hline
\end{tabular}

\section{Prevalence of Zika in Asia}

Asia is continent which contain various tropical countries. It is believed that there are high range of arboviruses diseases present like ZIKV, DENV and CHICKV. There are two linages of the ZIKV, one of them is African linage and other one is Asian linage. But according to new research all infected strains from different countries of Asia and America is from Asian linage (Yun et al. 2016). It is suggested that ZIKV in Asia is scary due to presence of DENV in Asia, both show similar symptoms.

Due to lack of public awareness related on ZIKV and considered as initial belief, less knowledge about neurological complications, this zika viral infection is considered as mild in character.

\section{Table 1: Asian countries with ZIKV autochthonous transmission}

While, the studies related to ZIKV in Asia contain several informative knowledge about infection. After outbreak of the 2007 in Yap, researches pay some attentions on the prevalence of the ZIKV. And describe ZIKV prevalence in Asia by scientific community. (Table 1).

\section{Mode of Infection of ZIKV}

Mode of infection of ZIKV has no details, researchers are still working to find th mechanism of action. Actually, confusion is this there a similar replication cycle for mostly flaviviruses describe in Fig. 2 . There are three protein structures for Flaviviruses, one of them is protein prM, second one is the $\mathrm{E}$ that is a protein of envelope and the last one is the capsid protein $\mathrm{C}$. There are numerous copies of the $\mathrm{C}$ protein which are present around the RNA genome of the virus that is situated around viral nucleocapsid. ZIKV entered inside of the cell is facilitated through the envelope proteins in three different stages. The initial stage is attachment of the virus particle on the surface of the cell. The next stage is the fusion of the outer layer of virus and layer of target cell and final stage is the attachment factors that encourage the viral infection by increasing the time period of contact between the virus and the surface of the target cell. 
Flaviviruses has been internalized in the cell through clathrin-mediated endocytosis, when virus enters in cell, it starts the uncoating of the nucleocapsid which are occurring here and the translation is done of RNA molecule into single polyprotein (Clyde et al. 2006). Thus, the procedure starts of the translocation on ER membrane in forward and backward manners. The next process co-translation and post-translation by protease enzymes of cellular. Virus-derived proteases into seven translational proteins proteins (NS1, NS2A, NS2B, NS3, NS4A, NS4B, and NS5) and three non-translational proteins (C, prM, and E).

The E protein is involved in correct folding of the protein because it is glycosylated (Bryant et al. 2007). Then, NS proteins is involved is initiation of replication of the viral genome and helps in manufactured new RNA is that packed into nucleocapsid through the $\mathrm{C}$ protein. The heterodimers are formed by the prM and $\mathrm{E}$ proteins which are oriented into the lumen of the ER. Furthermore, trimers are associated by the prM/E heterodimers. There are some oligomeric interactions are formed which are considered as they make a curved surface lattice, that directs the virion budding. Virus particles gathered here and forming the buds into the ER that are secreting out from the cell. The maturing of the virion particles is done during the egress in the acidic chambers of the Golgi apparatus (Rodenhuis-Zybert et al. 2010).

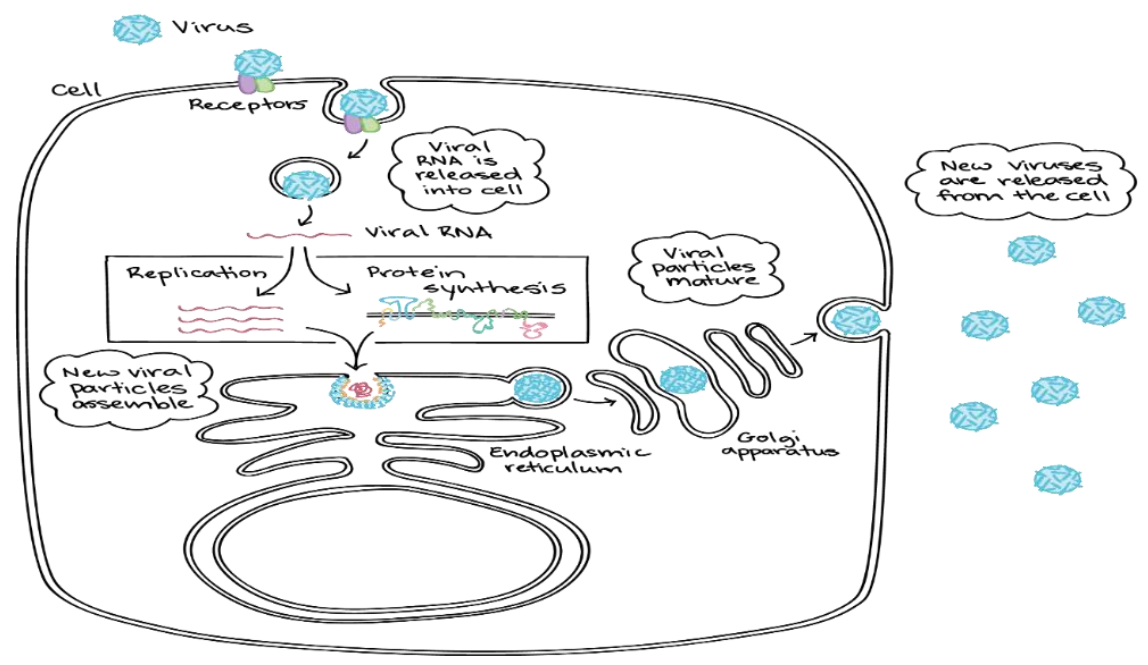

Fig.2: Mode of Infection of ZIKV

Appearance of Zika Virus

The incubation period of Zika V is more than two weeks. The signs which are due to ZIKV are similar to the symptoms caused by arbovirus. Usually, the symptoms which are appeared because of ZIKV include skin rashes, fever, joint pain, headache and muscle are describe in Fig 3. According to WHO in 2016, ZIKV infection during pregnancy causes some serious disorders like Guillain-Barre syndrome and microcephaly (Cerbino et al. 2016).

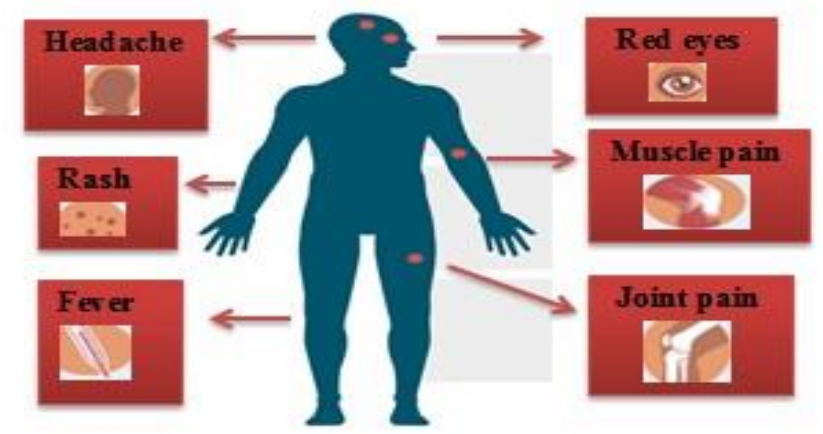




\section{Fig. 3: Appearance of Zika virus}

\section{Offensive Properties of Zika Virus Microcephaly}

Microcephaly is a health related problem, the size of head is smaller than normal size of the head. Microcephaly is classified into two categories in humans. One of them is happened when there is insufficient amount of neuron production which causes inappropriate growth of brain during 32 weeks of development stage and in other one initially the growth of brain is normal but in later on due to some abnormalities in dendritic portion of brain microcephaly causes (Mlakar et al. 2016). According to latest research it has been purposed that zika infection is a cause of microcephaly during pregnancy. There are many probabilities that new born baby can be suffered from the disease of microcephaly.

The fibroblast and keratinocytes of the targeted persons are usually affected by the zika infection. Antiviral genome expressed due to production of cytokines when Zika V effects the targeted placental macrophages. Zika viral particles enters into cell by intermingling with surface of cell and their receptors such as TYRO3 and AXL and TAM. Once ZIKV enters in the cells it causes changing in the genes which related with the cell cycle, cell differentiation, and apoptosis and it is concluded as such changes brain abnormalities arises. This is a type of brain abnormality which is categorized as microcephaly (Platt \& Miner, 2017).

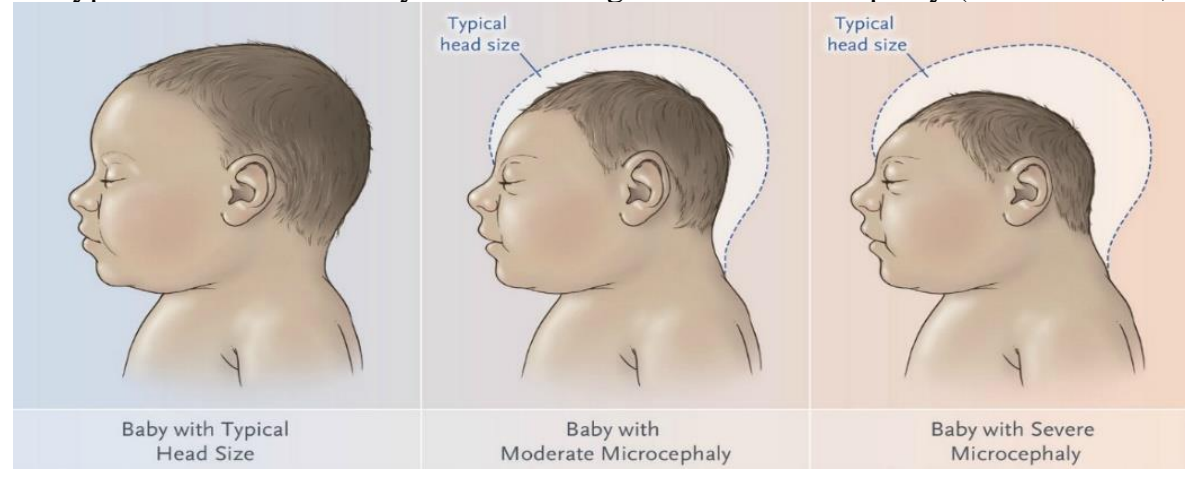

Fig. 4: symptoms of Microcephaly

\section{Guillain-Barre syndrome}

Guillain-Barre syndrome GBS is a serious syndrome of nervous system in which the immunity of person injured the nerve cells of the brain which cause the muscles weakness in some cases it causes the paralysis. According to recent research in America it is proposed that ZIKV is associated with Guillain-Barre syndrome and it was confirmed by MRI. It is an autoimmune neuropathy is attacked on PNS which further leads towards the weakness in muscle, paralysis and in some cases death (Pawitwar et al. 2017).

Major outbreak of GBS in French Polynesia in 2013-2014, there were more than 35 cases of ZIKV disease recognized. But the exact association of the GBS with ZIKV in not confirmed till yet. But in 2016 researches stated that ZIKV association with GBS was defined by demyelination, inflammation, and collapsing of blood-brain barrier. During the outbreak, researcher detected that $98 \%$ of patients of ZIKV contain anti-ZIKV IgM or IgG which diagnosed with GBS. Brazil is the most effected country from ZIKV that's why it is expected that there is a high risk of GBS in infected persons. There are also some possibilities that it can cause the other severe neurological problems (Dos et al. 2016; Blake et al. 2016).

\section{Diagnosis}

RT-PCR is used to detect the zika infection during the first week of infection which confirmed their indication. Severity of infection is confirmed from 0 to 10 days after symptom start (Lanciotti et al., 2007). Serologic testing Immunoglobulin M through ELISA is used to detect the presence of virus, while in some cases on 
DENV it gives some confused results. Therefore, positive results must be confirmed by assays. Actually, Zika viral infection can cause confusing results for DENV. Through saliva, urine and serum is used to detect the ZIKV RNA (Gourinat et al. 2015; Musso et al. 2015).

\section{a. Direct viral diagnosis}

RT-PCR is a technique which is used to diagnose the zika viral infection. The acute infection phase is supposed to be slight, so the virus can be noticed in the blood after showing the symptoms from day 0 to 4 . The total time that is compulsory for the recognition of RNA of virus in blood may also depend on the viral load during the acute period of the infection, because viremia become less over time. If the blood is collected after 5 to 7 days of appearance of symptoms thus PCR result will be negative in most viral infections but in case of flavivirus infection it will be positive. That's why serological testing is always considered (Atif et al. 2016).

Detection of ZIKV RNA is done by several other specimens for example through saliva and through urine at different time periods. (Fig. 1). When the symptoms initiate in a human thus the recognition period of RNA viral in saliva is less than 8 days. RNA in blood is considered as longer than the RNA in saliva. Though, it is an advantage of RNA in blood in longer due to non-invasive and it is considered as higher sensitivity in testing according to a study report (Musso et al. 2015). Like other flaviviruses, urine can also use for detection of ZIKV RNA (Barzon et al. 2013). Actually, it is advantageous to detect the ZIKV RNA in urine due to its longer duration then blood and remain positive for a long period of time (Musso et al. 2015; Gourinat et al. 2015). But still it is unclear and there is no data is valid that can be suggested the replacement of sample specimens, for example, blood with urine (Campos et al. 2016). It is suggested according to a report that ZIKV can be detected in an infected human semen for more than 21 days after beginning of symptoms (Musso et al., 2015), although there is another study has been reported for detection of Zika viral RNA in infected semen for more than 60 days after beginning of symptoms (Atkinson et al. 2016). There are also some other specimens to detect ZIKV RNA, for example amniotic fluid, cerebrospinal fluid and placental fluid (Martines et al. 2016).

\section{b. Serological diagnosis}

Laboratory examinations is done to detect the ZIKV RNA in infected persons, it is also suggested that all the symptoms of ZIKV are not specific. Serologic testing contains ELISA and IFA are used to detect the ZIKV Immunoglobulin $M$ antibodies after appearances of symptoms from 4 to 5 days. Mostly the time period to detect from specific IgM antibodies for ZIKV is 2 to 3 months, in some cases the time duration of the Immunoglobulin $\mathrm{G}$ antibodies is longer than $\operatorname{IgM}$ antibodies, so the detection can be done in more than 3 months. But unfortunately, there is no valid assay to detect the ZIKV serologically. Therefore, to detect the ZIKV serologically it is detected in the laboratory with expertises who can discriminate the flavivirus well (Atif et al. 2016).

In Asian countries are those countries who are affected recently from several arboviruses like DENV and CHIKNV. These viruses These viruses play a vital role to cause the false positive serological testing due to their interference as arboviruses. That's why there is a only way to find out the positive result the plaque reduction neutralization test. It is very specific test for flaviviruses that is virus neutralization tests. The most complicated diagnosis can be due to presence of the co- infection of ZIKV with other CHIKNV and DENV (Chen et al. 2016).

\section{Treatment, Prevention, and Control}

There is not any vaccine available for the proper treatment of ZIKV but there many preventions to avoid the infection. Zika viral infection is commonly insignificant because there is no precise treatment for zika viral infection. Usually, it is suggested that there should be high intake of fluid for diseased persons and they should take rest for longer intervals. There is only drug treatment suggested for ZIKV is acetaminophen, that is recommended for mild signs of fever, myalgia and headache. Severe itching of skin can be controlled with antihistamines, but in case of loss of body fluid through sweating and vomiting thus must be adjusted by adequate rehydration. Aspirin is a medicine that should not be taken by infected person who is at risk of bleeding due to thrombocytopenia (Chen et al. 2016). Due to the high risk of severe haemorrhagic complications, the non-steroidal and anti-inflammatory drugs should not used for cases of DENV, CHIKV 
and ZIKV. There are some neural complications, mostly Guillain-Barré syndrome, should be identified as soon as possible to allow early use of plasmapheresis and IV immunoglobulins (Chan et al. 2016).

The infected children and the other members of their family should be recommended by a multidisciplinary team consisting of pediatric neurologist, clinical geneticists and other related specialists. Moreover, it can long term follow up for monitoring physical, functional and other regular processes of an infected child and that family (Staples et al. 2016).

\section{Zika virus a threat for Pakistan}

According to WHO stated on May 15, 2017, India's health ministry reported in western state of Gujrat near the Sindh border of Pakistan. There were three confirmed cases of ZIKV. China is situated at northeast of Pakistan, who has also declared the confirmed its first case of Zika viral infection in February 2017 and in September 5, 22 some more cases were reported in China luckily all the patients had recovered. All this information about report cases of ZIKV suggested that there is low-level transmission of Zika Virus in SouthEast Asia Region but it's a threat for Pakistan because new cases that appear in the future, may arise in Pakistan (Afzal et al. 2015). Dengue mosquitos usually these are Aedes species of mosquitoes are vehicles for ZIKV in Pakistan because they are also source of Zika Virus is present in Pakistan, advised by, Dr. Muhammad Najeeb Durrani, one of the members of GOARN (Global Outbreak Alert and Response Network). His warning is due to latest outbreaks of ZIKV were previously described in the neighbouring countries India and China which are situated near the boundary of Pakistan. Most probably it is stated as ZIKV infection will enter from area of Sindh province of Pakistan near the western state of Gujarat because the Aedes species of mosquitoes are already present throughout in Pakistan (Fatima et al. 2016).

Although, there is no confirmed case of ZIKV has been recognized in Pakistan according to serological survey and there is no evidence of serological traces exists. There is a possible reason that might be due to incomprehensible the detection of ZIKV is the lack of proper screening system that can not differentiate ZIKV from other flaviviruses. The laboratory confirmation of ZIKV is challenging because of serological cross-reactivity with other flavivirus, particularly with DENV and CHIKNV. There is possibility, ZIKV has been entered into the Pakistan and is unreported or misdiagnosed still because due to low literacy rate many people do not visit doctor due to minor symptoms; secondly, ZIKV shares not only its vector Aedes aegypti with CHIKV and DENV but also the clinical features and geographic distribution. Long range dispersal of vector, mosquito Aedes aegypti is responsible for the rapid surge in viral infections. Punjab is the largest province of Pakistan and it is home of Aedes species of mosquito that is the principal vector carrying ZIKV.

The possible breeding season for Aedes species of mosquitoes is summer from July to September due to monsoon rainfalls. People who are living in slum areas of the Pakistan are at greater risk of zika viral infection due to standing water and open sewage drains that are breeding pockets for Aedes mosquito. It is expected that Karachi and Lahore, two largest cities of Pakistan are more susceptible cities to ZIKV outbreak because of rapid growth in slum areas and increasing growth of vector population. Not only Karachi and Lahore, there are some other urban areas especially Islamabad, Multan, Quetta, Gwadar, and Peshawar are the potential courses of ZIKV entry because of major airline traffic flow between pandemic regions. Mostly airlines are landing in cities of Punjab province which contain large number of vector population from infected other counties. Furthermore, recent study published in 'Lancet' revealed that the highest proportion of highrisk travellers who arrive from Singapore, Miami, USA, Florida, and Brazil can contribute to ZIKV transmission in Pakistan which are landing in different cities of Punjab. Mostly, civilians are understanding that's why they ignoring the spread of ZIKV in Pakistan due to low resources to detect the Zika viral infections on a large scale. However, the widely distributed significant high population of competent vector Aedes species of mosquito. It is suggested that the outbreak of ZIKV in Pakistan will more dangerous than Asian countries due to presence of large scale of Aedes species of mosquitoes in Pakistan. The infection will be very severe due to it neurological association (WHO 2018). Public health officials must do implements for robust surveillance through integrated mosquitoes control strategy because if once the virus begins spreading locally, it will become deep-rooted in population and will 
be extremely difficult to stop, that's why, there is only way to control the spread of ZIKV by reducing Aedes mosquito populations reducing human contact with mosquitoes vector. The increasing fear of ZIKV epidemic in Pakistan calls for corresponding effort of scientific community to address the strategies for controlling the spread of ZIKV. Actually, it is suggested that the outbreak of ZIKV will be much worse in Pakistan then Brazil due to large population rate and increasing number of new born babies per day, it will be more dangerous due to its neurological syndromes i.e GBS and microcephaly (Wahib et al.2018).

\section{Vaccine Approaches for Zika virus}

Different vaccines methods are established for Flavivirus. But there are only three vaccines are established for ZIKV as describe in figure 5. At this time, in different areas of the world scientists have tried at clinical level for production of the vaccine for ZIKV. But from all of three vaccines, there is only DNA vaccine which is effected for clinical trials at phase 2. mRNA vaccines for ZIKV is under developmental procedure yet because of its unique characteristic of no penetration into the host genome.

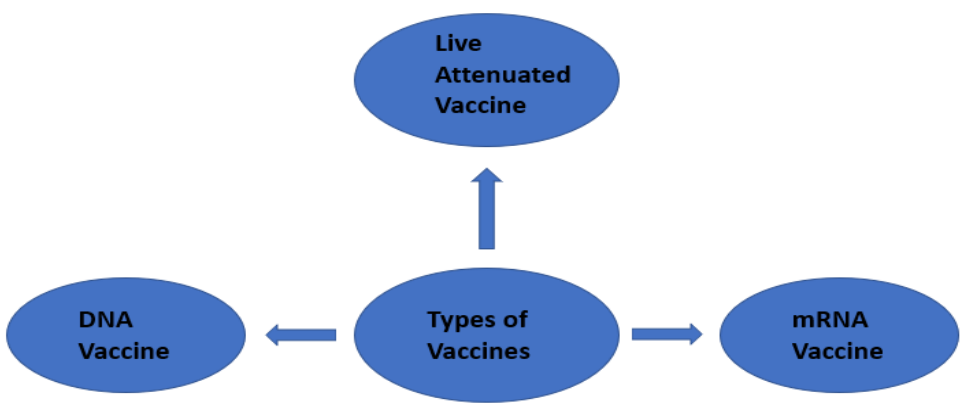

Fig. 5: Types of Vaccines

\section{DNA vaccines}

DNA vaccine for ZIKV was designed by the researcher of NIAID. In the mouse and monkey DNA vaccines is good for phase 1 trials and successfully persuade for defense. There are also performed to check their effect for human phase 2 trials. Brazil and America are such countries who suffer from major outbreaks of ZIKV that's why these are used for experimental purpose include 2,490 infected persons. Among them most of people show the important symptoms of the ZIKV (Larocca et al. 2016). Researchers injected the two genes into the small fragments of DNA for encoding the two proteins which were existing on the Zika viral surface, it was all done for the development of vaccine. To check the results of the vaccine it was introduced into the healthy person and the diseased person. It was shown that it activated the immune system of the person and there was no harmful. But it is not still designed for trade market because of their efficiency and safety problems. DNA vaccine is very effective for ZIKV because of its specific mode of action. (Yi et al. 2017). The procedure of production of DNA vaccine described in Fig 6. 


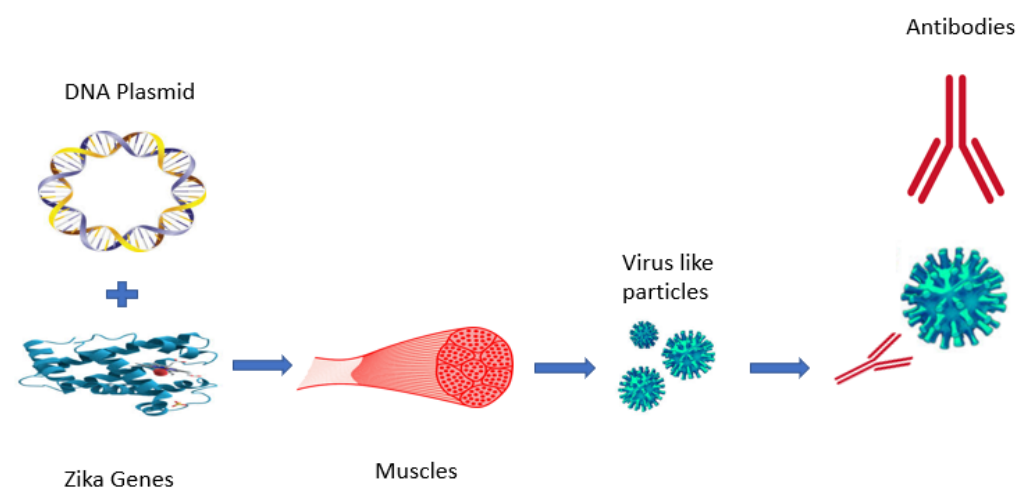

Fig. 6. Production of DNA vaccine

\section{Live attenuated vaccine}

Such type of vaccine is that kind of vaccine, viruses are sufficiently debilitated which are still able to show immunity and can protect us from ZIKV infection. Live attenuated vaccine shows vital advantages like single dose is enough for activation of immunity and which will be defensive for long period of time and remain live attenuated vaccine have various safety issues particularly in the case of ZIKV (Shan et al. 2017). Live attenuated vaccine is produced by scientist through deleting that a specific segment from the viral genome, it was produced by the similar way as developed the vaccine for DENV. These vaccines are very operative in mice and NHPs but it is not effective for humans. But the drawback, the vaccine does not show the proper effect against ZIKV. Features of live attenuated vaccine define in (Table 2) (Barouch et al. 2017).

\section{Table 2: Live Attenuated Vaccines against Zika Virus}

\begin{tabular}{|l|l|l|}
\hline Features & Live Attenuated & References \\
\hline Advantages & $\begin{array}{l}\text { Single dose, Long-lasting } \\
\text { immunity }\end{array}$ & (Oehler et al. 2014) \\
\hline Disadvantages & Safety and efficacy issues & (Oliveira et al. 2016) \\
\hline $\begin{array}{l}\text { In development for } \\
\text { Zika virus }\end{array}$ & Phase I Trials & (Oliveira et al. 2016) \\
\hline $\begin{array}{l}\text { Other Flavivirus } \\
\text { vaccines }\end{array}$ & $\begin{array}{l}\text { IMOJEV (JE), vaccine against } \\
\text { dengue }\end{array}$ & (Brasil et al. 2016) \\
\hline
\end{tabular}

\section{mRNA vaccine}

Messenger RNA vaccines contain an open reading frame that encoded antigen of interest thus decoded by the host cell. The unique property of RNA vaccine is that it does not penetrate into the host cell's genome, that is safest benefit than DNA vaccine (McArthur, 2017). Modified mRNAs programming lipid nanoparticles condensed and used for treatment against zika virus strain in mice. Then the scientists did some changes in four amino acids and use these modified RNA vaccines against mice. Production of RNA vaccine is costly but impressive that's why limited dose is enough to induce for the defensive immunity (Pardi et al. 2017). At this time, there is clinical Phase I trial of one mRNA vaccine is in development. The fundamental features of mRNA vaccine are defined in (Table 3) (McArthur, 2017).

Table 3: mRNA vvaccines against Zika virus 


\begin{tabular}{|l|l|l|}
\hline Features & mRNA Vaccines & References \\
\hline Advantages & Well tolerated, Rapid development. & (Rodolphe et al. 2015) \\
\hline Disadvantages & $\begin{array}{l}\text { New routes of immunization require trained } \\
\text { persons, Limited commercial scale } \\
\text { production. }\end{array}$ & (Brasil et al. 2016) \\
\hline $\begin{array}{l}\text { In development } \\
\text { for Zika }\end{array}$ & $\begin{array}{l}\text { Complete protection against Zika in animal } \\
\text { models. }\end{array}$ & (Rodolphe et al. 2015) \\
\hline $\begin{array}{l}\text { Other Flavivirus } \\
\text { vaccines }\end{array}$ & No licensed human vaccines. & (Brasil et al. 2016) \\
\hline
\end{tabular}

\section{Conclusion}

Vast majority of ZIKV globally increased day by day, the eruptions of viral infection have been detected and ways of transmission for ZIKV. The current research suggests that there should be lessen the non- vector transmission of ZIKV. There are some other modes of transmission through blood transfusion and transmission through sexual contact, nut the main source of the transmission of ZIKV is vector transmission like Aedes species of mosquitoes. The outbreaks of ZIKV are helpful to understand the infection of the Zika virus. In past due to low rate of infection of ZIKV, this issue was not considered as most important but in past few years it become a harmful to health. That's why scientist starts research to find out the better way to diagnose the infection and to cure the problem. It is a challenge to find out the accurate existing rate of ZIKV. Because the symptoms are imprecise and insignificant. The analysis is not possible of every infected area. There are some therapies which are used for the control of zika viral infection. Pakistan is a country which contain already the vector for transmission of the ZIKV and the infection was reported near the border of Pakistan, it is possible threat for Pakistan to face a major outbreak of ZIKV in near future. It is suggested to the government of Pakistan to make a better strategy to control the population of Aedes species of mosquitoes. At this time, there is no proper vaccination for zika viral infection. The utmost effective trials are done through the mRNA and DNA vaccine through inhibition of the protein synthesis mechanism of ZIKV and by action of targeting the RNA genome of the ZIKV.

\section{Summary}

Zika virus is an icosahedral, enveloped, single-stranded RNA virus, a member of the family Flaviviridae, transmitted to humans by Aedes species mosquitoes. Unique features of Zika virus infection are sexual and transplacental transmission and associated neurological morbidities. The main objective of our review is to summarize the all current information including epidemiology and pathophysiology of routes of transmission, prevalence, mode of infection, symptoms, diagnosis, treatment and vaccine strategies of Zika viral infection. This article is helpful to improve the treatment of Zika viral infection which will be beneficial for society. There are two different methods to diagnose the viral infection through RT-PCR and RNA NAT analysis. Vaccines have been developed against Zika virus, DNA vaccine effects actively due to its unique mode of infection. Treatment of Zika fever is supportive and primarily involves acetaminophen for fever, headache, or myalgia. ZIKV illness is generally mild in nature, requiring no specific treatment. The only pharmacological drug is prescribed by doctors is acetaminophen. As with treatment for dengue, nonsteroidal anti-inflammatory agents should be avoided if thrombocytopenia is present. The most successful trials are given by the DNA and mRNA vaccine which act by targeting the genome of the Zika virus or by inhibiting its protein synthesis mechanism. Vast majority of ZIKV globally increased day by day, the eruptions of viral infection have been detected and ways of transmission for ZIKV. The current research suggests that there should be lessen the non- vector transmission of ZIKV. There are some other modes of transmission through blood transfusion and transmission through sexual contact, nut the main source of the transmission of ZIKV is vector transmission like Aedes species of mosquitoes. The outbreaks of ZIKV are helpful to understand the infection of the Zika virus. In past due to low rate of infection of ZIKV, this issue was not considered as most important but in past 
few years it become a harmful to health. That's why scientist starts research to find out the better way to diagnose the infection and to cure the problem. It is a challenge to find out the accurate existing rate of ZIKV. Because the symptoms are imprecise and insignificant. The analysis is not possible of every infected area. There are some therapies which are used for the control of zika viral infection. Pakistan is a country which contain already the vector for transmission of the ZIKV and the infection was reported near the border of Pakistan, it is possible threat for Pakistan to face a major outbreak of ZIKV in near future. It is suggested to the government of Pakistan to make a better strategy to control the population of Aedes species of mosquitoes. At this time, there is no proper vaccination for zika viral infection. The utmost effective trials are done through the mRNA and DNA vaccine through inhibition of the protein synthesis mechanism of ZIKV and by action of targeting the RNA genome of the ZIKV. 


\section{References}

Afzal, M. F., Naqvi, S. Q., Sultan, M. A., \& Hanif, A. (2015). Chikungunya fever among children presenting with nonspecific febrile illness during an epidemic of dengue fever in Lahore, Pakistan. Merit Res J Med Med Sci, 3(3), 69-73.

Akoua-Koffi, C., Diarrassouba, S., Benie, V.B et al.(2001). Investigation surrounding a fatal case of yellow fever in Cote d'Ivoire in 1999. Bull Soc Pathol Exot . ; 94:227-30.

Aliota, M.T., Bassit, L., Bradrick, S.S., Cox, B., Gavegnano, C, et al. (2017) Zika in the Americas, year 2: What have we learned? What gaps remain? A report from the Global Virus Network. Antiviral Res 144: 223-246.

Althouse, B.M., Hanley, K.A., Diallo, M., et al. (2015). Impact of climate and mosquito vector abundance on sylvatic arbovirus circulation dynamics in Senegal. Am J Trop Med Hyg; 92:88-97.

Althouse, B.M., Vasilakis, N., Sall, A.A., Diallo, M., Weaver, S.C., Hanley, K.A. (2016). Potential for Zika virus to establish a sylvatic transmission cycle in the Americas. PLoS Negl Trop Dis 10:e0005055.

Arsuaga, M., Bujalance, S.G., Díaz-Menéndez. M., Vázquez, A., Arribas, J.R. (2016). Probable sexual transmission of Zika virus from a vasectomised man. Lancet Infect Dis ; 16:1107.

Atif, M., Azeem, M., Sarwar, M. R., \& Bashir, A. (2016). Zika virus disease: a current review of the literature. Infection, 44(6), 695-705.

Atkinson, B., Hearn, P., Afrough, B., Lumley, S., Carter, D., Aarons, E.J., (2016). et al. Detection of Zika virus in semen. Emerg Infect Dis. ;22:940.

Aubry, M., Richard, V., Green, J., Broult, J., Musso, D. (2016). Inactivation of Zika virus in plasma with amotosalen and ultraviolet A illumination. Transfusion,; 56:33-40.

Ayres, C.F. (2016). Identification of Zika virus vectors and implications for control. Lancet Infect Dis; $16: 278-9$.

Barjas-Castro, M.L, Angerami ,R. N., Cunha, M.S., et al. Probable transfusion-transmitted Zika virus in Brazil. Transfusion ; 56:1684-8.

Barouch, D.H., Thomas, S.J., Michael, N.L. (2017). Prospects for a Zika virus vaccine. Immunity. 46: 176182.

Barzon, L., Pacenti, M., Franchin, E, (2016). et al. Infection dynamics in a traveller with persistent shedding of Zika virus RNA in semen for six months after returning from Haiti to Italy, January Euro Surveill; 21. doi:10.2807/1560-7917. ES.2016.21.32.30316.

Barzon, L., Pacenti, M., Franchin, E., Pagni, S., Martello, T., Cattai, M., (2013). et al. Excretion of West Nile virus in urine during acute infection. J Infect Dis. 2013;208:1086-92.

Barzon, L., Trevisan, M., Sinigaglia, A., Lavezzo, E., \& Palu, G. (2016). Zika virus: from pathogenesis to disease control. FEMS microbiology letters, 363(18), fnw202.

Bennett, J. E., Dolin, R., Blaser, M. J. (2014). Principles and practice of infectious diseases (Vol. 1). Elsevier Health Sciences.

Blake, A.S., Mons, S., Lastere, C., Roche, J., Vanhomwegen J, et al. (2016). Guillain-Barré Syndrome outbreak associated with Zika virus infection in French Polynesia: a case-control study. Lancet, 387: 1531-1539.

Boeuf, P., Drummer, H.E., Richards, J.S., Scoullar, M.J., Beeson , J.G. (2016). The global threat of Zika virus to pregnancy: epidemiology, clinical perspectives, mechanisms and impact. BMC medicine. 14: 112 .

Brasil, P., Pereira, J.P., Moreira, M.E., Ribeiro, N.R.M. (2016). Zika virus infection in pregnant women in Rio de Janeiro. N Engl J Med .375: 2321-2334.

Brooks, R.B., Carlos, M.P., Myers, R.A. (2016). et al. Likely sexual transmission of Zika virus from a man with no symptoms of infection-Maryland, MMWR Morb Mortal Wkly Rep.; 65:915-6.

Bryant, J.E., Calvert, A.E., Mesesan, K., Crabtree, M.B., Volpe, K.E., Silengo, S., Kinney, R.M., Huang, C.Y., Miller ,B.R., Roehrig, J.T. (2007). Glycosylation of the dengue 2 virus E protein at N67 is critical for virus growth in vitro but not for growth in intrathoracically inoculated Aedes aegyptimosquitoes. Virology. 366:415-23. 
Buathong, R., Hermann, L., Thaisomboonsuk, B., Rutvisuttinunt, W., Klungthong, C., Chinnawirotpisan. P, et al. (2015). Detection of Zika virus infection in Thailand, 2012- 2014. Am J Trop Med Hyg 2015;93:380-3.

Buechler, C.R., Bailey, A.L., Weiler, A.M., et al. (2017). Seroprevalence of Zika virus in Wild African green monkeys and baboons. mSphere 2017; 2. doi:10.1128/ mSphere.00392-16.

Centers for Disease Control and Prevention. Case counts in the US. Atlanta, GA: CDC, 2017.

Cerbino-NJ, Mesquita EC, Souza TM, ParreiraV, Wittlin BB, et al. (2016) Clinical manifestations of Zika virus infection, Rio de Janeiro, Brazil 2015. Emerg Infect Dis 22: 1318-1320.

Chan, J.F., Choi, G.K., Yip, C.C., Cheng, V.C., Yuen, K.Y. (2016). Zika fever and congenital Zika syndrome: an unexpected emerging arboviral disease. J Infect. 72:507-24.

Chen, L.H., Hamer, D.H. (2016). Zika virus: rapid spread in the Western hemisphere. Ann Intern Med. 2016;164:613-5.

Chen, L.H. Zika virus infection in a Massachusetts resident after travel to Costa Rica: a case report. Ann Intern Med. 2016;164:574-6.

Chouin-Carneiro, T., Vega-Rua, A., Vazeille, M, et al. (2016). Differential susceptibilities of Aedes aegypti and Aedes albopictus from the Americas to Zika virus. PLoS Negl Trop Dis. 10:e0004543.

Ciota AT, Bialosuknia SM, Ehrbar DJ, Kramer LD. (2017). Vertical transmission of Zika virus by Aedes aegypti and Ae. albopictus mosquitoes. Emerg Infect Dis. 23:880-2.

Ciota, A.T., Bialosuknia, S.M., Zink, S.D., et al. (2017). Effects of Zika virus strain and Aedes mosquito species on vector competence. Emerg Infect Dis ; 23:1110-7.

Clyde, K., Kyle, J.L., Harris, E. (2006). Recent advances in deciphering viral and host determinants of dengue virus replication and pathogenesis. J Virol. ;80:11418-31.

D’Ortenzio, E., Matheron S, Yazdanpanah Y, et al. (2016). Evidence of sexual transmission of Zika virus. N Engl J Med 2016; 374:2195-8.

Darwish, M. A., Hoogstraal, H., Roberts, T. J., Ahmed, I. P., \& Omar, F. (1983). A sero-epidemiological survey for certain arboviruses (Togaviridae) in Pakistan. Transactions of the Royal Society of Tropical Medicine and Hygiene, 77(4), 442-445.

Davidson, A., Slavinski, S., Komoto, K., Rakeman, J., Weiss, D. (2016). Suspected female-tomale sexual transmission of Zika virus-New York City, 2016. MMWR Morb Mortal Wkly Rep. 65:716-7.

Deckard, D.T., Chung, W.M., Brooks, J.T, et al. (2016). Male-to-male sexual transmission of Zika virusTexas, January . MMWR Morb Mortal Wkly Rep. 65:372-4.

Di Luca, M., Severini, F., Toma, L., et al. (2016). Experimental studies of susceptibility of Italian Aedes albopictus to Zika virus. Euro Surveill. 21. doi:10.2807/15607917.ES.2016.21.18.30223.

Diagne, C.T., Diallo, D., Faye, O, et al. (2015). Potential of selected Senegalese Aedes spp. mosquitoes (Diptera: Culicidae) to transmit Zika virus. BMC Infect Dis. 15:492.

Diallo, D., Sall, A.A., Diagne, C.T., et al. (2014). Zika virus emergence in mosquitoes in southeastern Senegal, PLoS One. 9:e109442.

Dodson, B.L., Rasgon, J.L. (2017). Vector competence of Anopheles and Culex mosquitoes for Zika virus. Peer J .5:e3096.

Dos, S.T., Rodriguez, A., Almiron, M., Sanhueza, A., Ramon, P, et al. (2016). Zika virus and the GuillainBarré syndrome-case series from seven countries. N Engl J Med 375: 1598-1601.

Duong, V., Dussart, P., \& Buchy, P. (2017). Zika virus in Asia. International journal of Infectious diseases, 54, 121-128.

Dupont-Rouzeyrol, M., O’Connor, O., Calvez, E., Daures, M., John, M., Grangeon, J.P., et al. (2015). Co-infection with Zika and dengue viruses in 2 patients, New Caledonia. Emerg Infect Dis. 21:381-2.

Ellison, D. W., Ladner, J. T., Buathong, R., Alera, M. T., Wiley, M. R., Hermann, L., ... \& Melendrez, M. C. (2016). Complete genome sequences of Zika virus strains isolated from the blood of patients in Thailand in 2014 and the Philippines in 2012. Genome Announc., 4(3), e00359-16.

Fagbami, A.H.(1979). Zika virus infections in Nigeria: virological and seroepidemiological investigations in Oyo State. J Hyg (Lond). 83:213-9. 
Fatima, S. H., Atif, S., Rasheed, S. B., Zaidi, F., \& Hussain, E. (2016). Species Distribution Modelling of Aedes aegypti in two dengue-endemic regions of Pakistan. Tropical Medicine \& International Health, 21(3), 427-436.

Fernandez, E., Diamond, M.S. (2017). Vaccination strategies against Zika virus. Curr Opin Virol 23: 5967.

Fonseca, K., Meatherall, B., Zarra, D., Drebot, M., MacDonald, J., Pabbaraju, K., et al. (2014). First case of Zika virus infection in a returning Canadian traveler. Am J Trop Med Hyg. 91:1035-8.

Food and Drug Administration. Revised recommendations for reducing the risk of Zika virus transmission by blood and blood components. (2017). https://www.fda.gov/downloads/BiologicsBloodVaccines/Guidance Compliance Regulatory Information/ Guidances/Blood/UCM518213..

Foy, B.D., Kobylinski, K.C., Chilson Foy, J.L., et al. (2011). Probable non-vector-borne transmission of Zika virus, Colorado, USA. Emerg Infect Dis. 17:880-2.

Freour, T., Mirallie, S., Hubert, B., et al. (2016). Sexual transmission of Zika virus in an entirely asymptomatic couple returning from a Zika epidemic area, France. Euro Surveill. 21. doi:10.2807/1560-7917.ES.2016.21.23.30254.

Galel, S.A., Williamson, P.C., Busch, M.P., et al. (2017). Cobas Zika IND Study Group. First Zika-positive donations in the continental United States. Transfusion.57:762-9.

Gourinat, A.C., O’Connor, O., Calvez, E., Goarant, C., Dupont-Rouzeyrol, M. (2015). Detection of Zika virus in urine. Emerg Infect Dis. 2015;21:84-6.

Gourinat, A., O’Connor, O., Calvez, E., Goarant, C., \& Dupont-Rouzeyrol, M. (2015). Detection of Zika Virus in Urine. Emerging Infectious Diseases, 21(1), 84-86.

Govero, J., Esakky, P., Scheaffer, S.M (2016). et al. Zika virus infection damages the testes in mice. Nature. 540:438-42.

Grard, G., Caron, M., Mombo, I.M., et al. (2014). Zika virus in Gabon (Central Africa): a new threat from Aedes albopictus? PLoS Negl Trop Dis. 8:e2681.

Gubler, D.J. (2002). The global emergence/resurgence of arboviral diseases as public health problems. Arch Med Res. 33:330-42.

Guo, X.X., Li, C.X., Deng, Y.Q., et al. (2016). Culex pipiens quinquefasciatus: a potential vector to transmit Zika virus. Emerg Microbes Infect. 5:e102.

Haddow, A.D., Nalca, A., Rossi, F.D., et al. (2017). High infection rates for adult macaques after intravaginal or intrarectal inoculation with Zika virus. Emerg Infect Dis. 23:1274-81.

Haddow, A.D., Schuh, A.J., Yasuda, C.Y., Kasper, M.R., Heang, V., Huy, R, et al. (2012). Genetic characterization of Zika virus strains: geographic expansion of the Asian lineage. PLoS Negl Trop Dis. 6:e1477.

Hahn, M.B., Eisen, R.J., Eisen, L., et al. (2016). Reported distribution of Aedes (Stegomyia) aegypti and Aedes (Stegomyia) albopictus in the United States, 1995-2016 (Diptera: Culicidae). J Med Entomol. 53:1169-75.

Heitmann, A., Jansen, S., Luhken, R, et al. (2017). Experimental transmission of Zika virus by mosquitoes from central Europe. Euro Surveill. 22. pii:30437.

Hennessey, M., Fischer, M., Staples, J.E. (2016). Zika virus spreads to new areas-region of the Americas, May 2015-January 2016. Am J Transplant. 16: 1031-1034.

Herrera, B.B., Chang, C.A., Hamel, D.J., et al. (2017). Continued transmission of Zika virus in humans in West Africa, 1992-2016. J Infect Dis. 215:1546-50.

Hirayama, T., Mizuno, Y., Takeshita, N., Kotaki, A., Tajima, S., Omatsu, T, et al. (2012). Detection of dengue virus genome in urine by real-time reverse transcriptase PCR: a laboratory diagnostic method useful after disappearance of the genome in serum. J Clin Microbiol. 50:2047-52.

Jimenez, A., Shaz, B.H., Bloch, E.M. (2017). Zika virus and the blood supply: what do we know? Transfus Med Rev .31: 1-10.

Kindhauser, M. K., Allen, T., Frank, V., Santhana, R. S., Dye, C. (2016). Zika: the origin and spread of a mosquito-borne virus. Bulletin of the World Health Organization. 94(9), 675. 
Kokernot, R.H., Casaca, V.M., Weinbren, M.P., McIntosh, B.M. (1965). Survey for antibodies against arthropod-borne viruses in the sera of indigenous residents of Angola. Trans $R$ Soc Trop Med Hyg 1965. 59:563-70.

Kuehnert, M.J., Basavaraju, S.V., Moseley, R.R., et al. (2016). Screening of blood donations for Zika virus infection-Puerto Rico, April 3-June 11, 2016. MMWR Morb Mortal Wkly Rep. 65:627-8.

Lanciotti, R. S., Kosoy, O. L., Laven, J. J., Velez, J. O., Lambert, A. J., Johnson, A. J., ... \& Duffy, M. R. (2008). Genetic and serologic properties of Zika virus associated with an epidemic, Yap State, Micronesia. Emerging infectious diseases, 14(8), 1232.

Larocca, R.A., Abbink, P., Peron ,J.P., Zanotto, P.M., Iampietro, M.J, et al. (2016). Vaccine protection against Zika virus from Brazil. Nature. 536: 474-478.

Laughhunn, A., Santa Maria, F., Broult, J, et al. (2017). Amustaline (S-303) treatment inactivates high levels of Zika virus in red blood cell components. Transfusion. 57:779-89.

Leal WS. (2016). mosquito vectors: the jury is still out. F1000Res . 5:2546.

Ledermann, J.P., Guillaumot, L., Yug, L., et al. (2014). Aedes hensilli as a potential vector of chikungunya and Zika viruses. PLoS Negl Trop Dis. 8:e3188.

Li, C.X., Guo, X.X., Deng, Y.Q, et al. (2017). Vector competence and transovarial transmission of two Aedes aegypti strains to Zika virus. Emerg Microbes Infect. 6:e23.

Liu, Z., Zhou, T., Lai, Z, et al. (2017). Competence of Aedes aegypti, Ae. albopictus, and Culex quinquefasciatus mosquitoes as Zika virus vectors, China. Emerg Infect Dis. 23:1085-91.

Mansuy, J.M., Dutertre, M., Mengelle, C., et al. (2016). Zika virus: high infectious viral load in semen, a new sexually transmitted pathogen? Lancet Infect Dis. 16:405.

Mansuy, J.M., Dutertre, M., Mengelle, C., Fourcade, C., Marchou. B, et al. (2016). Zika virus: high infectious viral load in semen, a new sexually transmitted pathogen. Lancet Infect Dis. 16: 405.

Mansuy,, J.M., Suberbielle, E., Chapuy-Regaud, S, et al. (2016). Zika virus in semen and spermatozoa. Lancet Infect Dis. 16:1106-7.

Martines, R.B. (2015). Notes from the field: evidence of Zika virus infection in brain and placental tissues from two congenitally infected newborns and two fetal losses-Brazil, MMWR Morb Mortal Wkly Rep. 65.

McArthur, M.A. (2017) Zika Virus: Recent Advances towards the Development of Vaccines and Therapeutics. Viruses. 9: 143.

Mlakar, J., Korva, M., Tul, N., Popović, M . (2016). Zika virus associated with microcephaly. N Engl J Med. 374: 951-958.

Motta, I.J., Spencer, B.R., Cordeiro, da Silva, et al. (2016). Evidence for transmission of Zika virus by platelet transfusion. $N$ Engl J Med ; 375:1101-3.

Musso, D., Gubler, D.J. (2016). Zika virus. Clin Microbiol Rev ; 29:487-524.

Musso, D., Nhan, T., Robin, E., et al. (2013). Potential for Zika virus transmission through blood transfusion demonstrated during an outbreak in French Polynesia, November 2013 to February (2014). Euro Surveill; 19. pii:20761.

Musso, D., Roche, C., Nhan, T.X., Robin, E., Teissier, A., Cao-Lormeau, V.M. (2105). Detection of Zika virus in saliva. J Clin Virol Off Publ Pan Am Soc Clin Virol. ;68:53-55.

Musso, D., Roche, C., Robin, E., Nhan, T., Teissier, A., Cao-Lormeau, V.M. (2015). Potential sexual transmission of Zika virus. Emerg Infect Dis ; 21:359-61.

Musso D, Roche C, Robin E, Nhan T, Teissier A, Cao-Lormeau VM. Potential sexual transmission of Zika virus. Emerg Infect Dis. 2015;21:359-61.

Musso, D., Roche, C., Robin, E., Nhan, T., Teissier, A., et al. (2015) Potential sexual transmission of Zika virus. Emerg Infect Dis. 21: 359.

Musso, D., Roche, C., Nhan, T. X., Robin, E., Teissier, A., \& Cao-Lormeau, V. M. (2015). Detection of Zika virus in saliva. Journal of Clinical Virology, 68, 53-55.

Nicastri, E., Castilletti, C., Liuzzi, G., Iannetta, M., Capobianchi, M.R. (2016). Ippolito G. Persistent detection of Zika virus RNA in semen for six months after symptom onset in a traveller returning from Haiti to Italy. Euro Surveill 2016; 21. doi:10.2807/1560-7917.ES.2016.21.32.30314. 
Oehler, E., Watrin, L., Larre, P., Leparc-Goffart, I., Lastere, S et al. (2014). Zika virus infection complicated by Guillain-Barre syndrome--case report, French Polynesia, December 2013. Euro Surveill: bulletin Europeensur les maladies transmissibles=European communicable disease bulletin. 6: 9.

Oliveira, M.A.S., Malinger, G., Ximenes, R., Szejnfeld, P.O., Alves, S.S., et al. (2016) Zika virus intrauterine infection causes fetal brain abnormality and microcephaly: tip of the iceberg? Ultrasound Obstet Gynecol. 47: 6-7.

Pardi, N., Hogan, M.J., Pelc, R.S., Muramatsu, H., Andersen, H., et al. (2017). Zika virus protection by a single low-dose nucleoside-modified mRNA vaccination. Nature. 543: 248-251.

Pawitwar, S.S., Dhar, S., Tiwari, S .(2017) .Overview on the Current Status of Zika Virus Pathogenesis and Animal Related Research. J Neuroimmune Pharmacol .12: 371-388.

Pealer, L.N., Marfin, A.A., Petersen, L.R, et al. (2003). Transmission of West Nile virus through blood transfusion in the United States in 2002. N Engl J Med. 1236-45.

Petersen, E.E., Meaney-Delman, D., Neblett-Fanfai,r R, et al. (2016). Update: interim guidance for preconception counseling and prevention of sexual transmission of Zika virus for persons with possible Zika virus exposure_-United States, September. MMWR Morb Mortal Wkly Rep; 65:107781.

Petersen, L.R., Jamieson, D.J., Honein, M.A., (2016). Zika virus. N Engl J Med 2016; 375:294-5.

Petersen, L. R., Jamieson, D. J., Powers, A. M., \& Honein, M. A. (2016). Zika virus. New England Journal of Medicine, 374(16), 1552-1563.

Platt, D.J, Miner, J.J. (2017). Consequences of congenital Zika virus infection.Curr Opin Virol. 27: 1-7.

Pompon, J., Morales-Vargas, R., Manuel, M., (2017). A Zika virus from America is more efficiently transmitted than an Asian virus by Aedes aegypti mosquitoes from Asia. Sci Rep ; 7:1215.

Radke, E.G., Gregory, C.J,, Kintziger, K.W., et al. (2009). Dengue outbreak in Key West, Florida, USA, . Emerg Infect Dis ; 18:135-7.

Ragan, I.K., Blizzard, E.L., Gordy, P,, Bowen, R.A., (2017). Investigating the potential role of North American animals as hosts for Zika virus. Vector Borne Zoonotic Dis; 17:161-4.

Reiter, P., Lathrop, S., Bunning, M., et al. (2003). Texas lifestyle limits transmission of dengue virus. Emerg Infect Dis ; 9:86-9.

Rodenhuis-Zybert, I.A., Wilschut, J., Smit, J.M. (2016). Dengue virus life cycle: viral and host factors modulating infectivity. Cell Mol Life Sci. 2010;67:2773-86.

Rodolphe, H., Ophélie, D., Sineewanlaya, W., Peeraya, E, Aymeric N, et al. (2015) Biology of Zika virus infection in human skin cells. J Virol. 89: 8880-8896.

Roundy, C.M., Azar, S.R., Rossi, S.L, et al. (2017). Variation in Aedes aegypti mosquito competence for Zika virus transmission. Emerg Infect Dis; 23:625-32.

Shan, C., Muruato, A.E., Jagger, B.W., Richner, J., Nunes, B.T., et al. (2017) A single-dose live-attenuated vaccine prevents Zika virus pregnancy transmission and testis damage. Nature Communications. 8 : 676.

Staples, J.E., Dziuban, E.J., Fischer, M., Cragan, J.D., Rasmussen, S.A., Cannon, M.J, et al. (2016). Interim guidelines for the evaluation and testing of infants with possible congenital Zika virus infection-United States, MMWR Morb Mortal Wkly Rep. 2016;65:63-7.

Tang, W.W., Young, M.P., Mamidi,A., Regla-Nava, J.A., Kim, K., Shresta, S. (2016). A mouse model of Zika virus sexual transmission and vaginal viral replication. Cell Rep 2016; 17:3091-8.

Thangamani S, Huang J, Hart CE, Guzman H, Tesh RB. Vertical transmission of Zika virus in Aedes aegypti mosquitoes. Am J Trop Med Hyg 2016; 95:1169-73.

Thomas, D.L., Santiago, G.A., Abeyta, R., et al. (2016). Reemergence of dengue in southern Texas, 2013. Emerg Infect Dis, 22:1002-7.

Villamil, W.E., Rodríguez, A.J., Uribe-García, A.M., González-,A.E., Castellanos, J.E. (2016). Zika, dengue, and chikungunya co-infection in a pregnant woman from Colombia. Int J Infect Dis, 51: $135-138$. 
Wahid, B., Ali, A., Rafique, S., \& Idrees, M. (2018). Zika virus: Is Pakistan next?. Asian Pacific Journal of Tropical Medicine, 11(7), 451.

Wikan, N., Suputtamongkol, Y., Yoksan, S., Smith, D.R., Auewarakul, P. (2016). Immunological evidence of Zika virus transmission in Thailand. Asian Pac J Trop Med 9:141-4.

Wikan, N., \& Smith, D. R. (2016). Zika virus: history of a newly emerging arbovirus. The Lancet Infectious Diseases, 16(7), e119-e126.

Wong, P.S., Li, M.Z., Chong, C.S., Ng LC, Tan CH. Aedes (Stegomyia) albopictus (Skuse): a potential vector of Zika virus in Singapore. PLoS Negl Trop Dis 2013; 7:e2348.

World Health Organization. (2016). Zika virus, microcephaly and Guillain-Barré syndrome situation report.

Yi, G., Xu, X., Abraham, S., Petersen, S., Guo H. (2017). A DNA Vaccine Protects Human Immune Cells against Zika Virus Infection in Humanized Mice. EBio Medicine; 25: 87-94.

Yitades, G., Nikkiah, F., Teshome, G. (2016). Zika virus infection, transmission, associated neurological disorders and birth abnormalities: A review of progress in research, priorities and knowledge gaps. Asian Pac J Trop Biomed. 6: 815-824.

Yun, S.I., Song, B.H., Frank, J.C., Julander, J.G., Polejaeva, I.A., Davies, C.J., White, K.L., Lee, Y.M. (2016). Complete genome sequences of three historically important, spatiotemporally distinct, and genetically divergent strains of Zika virus: MR-766, P6-740, and PRVABC-59. Genome Announc;4:pii:e00800-16. 